\title{
Seeing the World Second Hand Mad Men and the Vintage Consumer
}

\section{CAROLINE HAMILTON}

UNIVERSITY OF MELBOURNE

Mad Men was the first television series to be produced by the US cable station American Movie Classics (AMC). Until the series launched in 2007 the network was known to viewers mostly for its re-runs of old films. The channel's reputation for nostalgic programming made it the ideal home for a series that returned to $1960 \mathrm{~s}$ America to explore the social effects of the advertising industry in the wake of the postwar consumer boom. Like other premium cable television shows such as The Wire and The Sopranos, Mad Men rapidly attracted a highly devoted following, but unlike the gritty realities of everyday American life offered by those shows, Mad Men offered a self-consciously stylised and stylish presentation of the past. According to early reviews, this was understood as the primary purpose of the production. The reviewer at the Los Angeles Times, for instance, provided readers with a two-line gloss on the show that read:

Set in a Madison Avenue ad agency in 1960, 'Mad Men' has the storied look of 'The Apartment', 'Bewitched' and a retro boutique all rolled into one. Men in slim suits and white shirts, women in pointy bras and sweater sets, 
all sideways smiles and white hip patter amid the rattle of ice cubes and the tiny clatter of lighters. ${ }^{1}$

Reviews like this implied that to enjoy Mad Men one needed only an appreciation of the original 'American movie classics' in which its host channel specialised, a concept that generated somewhat unexpected audience excitement: that this contemporary television series looked so convincingly like the set of an old movie animated fans to take to blogs and message-boards to share their obsession with what one fan described as 'the tiny details that are just so perfect'.

I get totally absorbed by the blonde furniture, the wardrobes, hair-styles, thick plastic-lensed glasses, and make-up.

[What] also makes the show brilliant is the art direction, even the sound.

Those typewriters, those cigarette lighters, the clicking of the heels. ${ }^{2}$

Now entering its fifth season, the audience's pleasure with those tiny details has not diminished. While Mad Men has never boasted the kind of ratings that can qualify it as a mainstream success, the show's impact on popular culture has been widespread. ${ }^{3}$ Setting the program in the world of Madison Avenue's burgeoning advertising industry drew attention to the long-neglected social and cultural history of advertising industry. Publishers took advantage of viewers' new-found interest by producing titles like Kings of Madison Avenue: The Unofficial Guide to Mad Men, Mad Men Unbuttoned: A Romp Through 1960s America, and The Real Mad Men: The Remarkable True Story of Madison Avenue's Golden Age.4 More significant than these books devoted to unpicking the fictional and historical development of consumer culture was the show's instigation of a full-blown consumer fever for all things midcentury: fashions, lifestyles and the art and design of consumer America. Magazines like GQ, Vogue and Vanity Fair not only put the stars of the show on their covers but presented readers with style instructions for their own lives: how to replicate the look of the Sterling Cooper offices, Betty Draper's kitchen or Joan Holloway's silhouette. The US clothing retailer Banana Republic, in partnership with the show's creators, used the distinctive 1960s look as inspiration for a nationwide fashion campaign; Brooks Brothers produced a suit based upon that worn by leading man Don Draper (itself based on a 1960s Brooks Brothers original); a nail polish company released a Mad Men-inspired line of colours. Consumer tie-in 
opportunities are obviously a lucrative alternative revenue stream for a program that reportedly costs $\$ 2.84$ million to produce per episode but Mad Men's popularity is more than a marketing initiative. ${ }^{5}$ It has had knowing homages from TV stalwarts Sesame Street and The Simpsons and spawned the Unofficial Mad Men Cookbook and Mad Men-inspired Halloween costumes, cocktail parties and theme weddings. All these attest to the show's status as a social meme. When the show returned to television for its fifth season early in 2012 the story made frontpage news.

Yet, not everyone is crazy for Mad Men. The show's ability to generate consumer heat has been interpreted by some television and cultural critics as direct evidence of its weakness as genuine television art. Mad Men has been accused by some of being primarily interested in selling audiences on the 1960s, trading consumer nostalgia for genuine historicity. Mark Greif, writing for the London Review of Books, remarks, for example:

The actresses are beautiful, the Brilliantine in the men's hair catches the light, and everyone and everything is photographed as if in stills for a fashion spread. The show's '1950s' is a strange period that seems to stretch from the end of World War Two to 1960, the year the action begins. The less you think about the plot the more you are free to luxuriate in the low sofas and Eames chairs, the gunmetal desks and geometric ceiling tiles and shiny IBM typewriters. Not to mention the lush costuming: party dresses, skinny brown ties, angora cardigans, vivid blue suits and ruffled peignoirs, captured in the pure dark hues and wide lighting ranges that Technicolor never committed to film. ${ }^{6}$

According to Greif, Mad Men devotes itself to the pursuit of a nostalgic style at the expense of genuine attempts to grapple with the legacy of the past. He takes exception, for instance, to the way the show invites the audience to take pleasure in 'looking at' the past, even while it draws attention to the many undesirable aspects of that history (for example, sexism, racism and homophobia). Grief believes this only gratifies audiences by presenting them with artfully constructed scenes of people looking good while doing the wrong thing. This suspicion regarding the popularity of Mad Men is shared by Daniel Mendelsohn, who, in an essay for the New York Review of Books in 2011, proposed that the audience's delight at and enjoyment 
of the show's mid-century aesthetics demonstrates a failure to fully conceive the significance of the past. Mendelsohn accounts for this by noting:

most of the people who are so addicted to the show are either younger adults, to whom its world represents, perhaps, an alluring historical fantasy of a time before the present era's seemingly endless prohibitions against pleasures once taken for granted (casual sex, careless eating, excessive drinking, and incessant smoking); or younger baby boomerspeople in their forties and early fifties who remember, barely, the show's 1960s setting, attitudes, and look.7

Mad Men's appeal to this demographic, Mendelsohn suggests, is an example of inauthentic nostalgia: only those who cannot remember the period would long to return there, and only then because they are lured by a world made of appealing surfaces. This downgrading of Mad Men from serious drama to nostalgic fantasy is a recurrent critical strategy among a certain strand of reviewers keen to distinguish themselves from the popular hype. In another review, this time for the online magazine Slate, Patrick Radden Keefe expresses a more equivocal anxiety. While still enjoying the show's artful design, he worries the use of historical artefacts serves to reinforce an ephemeral present rather than consolidate historically grounded understanding of the past: Mad Men is 'a delicious but ultimately meaningless immersion in style over substance'.8

Can there be more to the audience's enjoyment of Mad Men's use of costume and design than empty gratification? If Mad Men emphasised other non-material aspects of history in order to transport its audience back in time, would it be regarded as a more genuine and serious attempt to grapple with history, rather than an exercise in retrogressive consumer nostalgia? In this essay I want to suggest an approach to understanding audience excitement for Mad Men's representation of the mid twentieth century that goes beyond the typical explanation of 'style over substance'. Readings of Mad Men which propose the show's foregrounding of material artefacts from the past is simply an exercise in window dressing impose a false binary, implying that any element of style cannot have substantive impact on the meaning of a text. These readings also assume that interest in the past, and particularly in the material culture of the past, is symptomatic of a conservative and superficial nostalgia, implying that historicity is the only acceptable mode of 
engaging with the past, and that taking pleasure in looking back stems from a desire to disassociate oneself from the present.

Mad Men is not the first media text to be accused of trivialising history for the sake of gratifying audiences. The popularity of heritage films and period pieces such as those produced by Merchant Ivory in the 1980s were criticised by film scholars for curating a 'museum aesthetic' that spoke to audiences in search of self-approving cultural elevation rather than accurate, deep engagements with history. ${ }^{9}$ Joseph Hipsky observes of such films, for example, that '[c]ritics regularly toast their ... sophisticated themes and gorgeous landscapes, architecture, and costumes. Reviewers celebrate their work as "highly literary" ... even as marketers of styleclothing, accessories, design, interior decoration, architecture-borrow from their ... fashions.' 10 The implicit conclusion here is that such responses are inappropriate. A good historical film must not set a social trend. Period-specific details may be impressive, but they ought not be the focus of serious art. Yet, Mad Men challenges the authority of such pronouncements. As the selection committee of the Peabody Award for media excellence and achievement noted when it presented Mad Men with its 2007 award, the tiny details represent in microcosm the complexity of the large social themes:

This shrewd account of American culture sliding into the 1960s, holding by fingernails onto the attitudes of the post-WWII 1950s, is as sharp as the creases in the two button suits, as precise as a narrow-knotted necktie, as wry as the rye on the bar. It also reminds us of the sexism at home in the suburbs, of life as constricting as the corsets and the pearl chokers. ${ }^{11}$

Mad Men mobilises objects and visual design from mid-century America to establish the role of material things in characterising the complexity of individuals, their relationships to one another, and society more broadly. Audiences delight in undertaking the work of understanding these relationships within the frame of the narrative and, as the program's adoption as a creative touchstone for consumers demonstrates, also delight in mobilising similar objects to similar ends in their own lives. Significantly, critics of Mad Men who have dismissed the show for its consumer nostalgia fail to note the show's popularity comes at a time when the consumer desire to invest in the significance and value of objects from the past has become a notable cultural trend. 
-'WE ARE ALL HOUSEKEEPERS NOW'

The ascent of Mad Men to popular acclaim mirrors several other globally successful cable television programs; Mad Men differs from these other programs is in its manifestation of an immersive, transmediated pop culture aesthetic amongst its fans. Few devotees of The Wire or The Sopranos express a desire to replicate the backrooms of the Bada Bing Club, or the crack-houses of downtown Baltimore, not to mention the sartorial stylings of a Carmella Soprano or an Avon Barksdale. This immersive engagement is the most distinctive aspect of Mad Men's popularity: the show shares its passion for material history with its viewers. A recent article in the Australian edition of the Big Issue points out, for example, that in Mad Men 'the clothes, the coffee tables and the cigarette holders are gorgeous details, but what makes them penetrate the part of your brain that drives you to visit [charity] shops?'12 In this respect Mad Men serves a function beyond water cooler conversation, it has become, in the words of sociologist Ann Deslandes, 'the exemplary current pop culture platform for the vintage aesthetic'. ${ }^{13}$ This effect owes much to the show's creator and head writer, Matthew Weiner. Weiner earned himself a reputation early in the show's production for his tendency to focus obsessively on the material accuracy of his show. Much has been made, for instance, of his insistence that the fruit that was to adorn a kitchen countertop had to be replaced because its size and shape betrayed its origins in the twenty-first century. ${ }^{14}$ Such scrupulous attention to detail has made Weiner a subject of fascination to the media who have used anecdotes like these to construct a sketch of a man with an almost autistic auteurism. In one interview, the journalist makes much of the fact that Weiner, having 'one grandfather in the fur business, the other in shoes', has a connoisseur's pedigree, as if this ancestry made Weiner destined to be a fastidious reader of material culture. 15

Mad Men is not the originator of the cultural fashion for the past but serves as a noteworthy example of the increasingly mainstream popularity for vintage consumption. The writers for AMC's website have even formulated their own awkward verb to describe this: 'to Mad Men oneself'. ${ }^{16}$ At the official website fans can play a game that presents a cartoon version of themselves to be styled in costumes typical of the era and the program: the old-fashioned, new 'you' can sip from martini glasses, smoke cartoon cigarettes, set a silk scarf at a jaunty angle 
while toting leopard-skin luggage and, when complete, the finished look can be set against a favourite Mad Men scene and downloaded. While the myriad crossmarketing opportunities that have presented themselves mean it is possible to 'Mad Men yourself' virtually, or in the local mall, the real pleasure-a pleasure the show itself demonstrates; and to which its significant production budget testifies-is to be found in the collection and curatorship of vintage originals. This means circumventing the mall in favour of second-hand shopping locations: charity shops, antique stores, garage sales, or car boot markets.

Even ten years ago old goods that were 'antiquated yet vaguely familiar' would have been described as 'retro,' but in recent years, as habits of global consumerism have changed, the word 'vintage' has gradually achieved widespread cultural currency. ${ }^{17}$ Borrowed from its use in wine terminology, anything now described as vintage connotes the application of principles of connoisseurship regarding the consumption, presentation, care and preservation of old objects. Vintage shopping places emphasis on the second-hand item as having value for the consumer according to its age, rather than pre-possession (thus removing some of the stigma otherwise attached to second-hand goods). Vintage items retain, in the words of sociologist Grant McCracken, their 'patina'-a property of goods by which their age becomes a key index of their status. ${ }^{18}$ Many of the activities associated with retro and vintage consumption are the same (visiting particular locations, using particular language and specific knowledge); however, where the term retro emphasises the consumer's approach or philosophy of 'looking back in order to move forward' the more recent term vintage emphasises the expertise of the consumer in applying this approach. ${ }^{19}$ If the popularity of earlier period dramas like those produced by Merchant Ivory was attributed to their construction of a 'museum aesthetic' for their viewers, Mad Men's popularity might be attributed to its production of a vintage aesthetic: presenting mid-century America as an emporium of carefully selected, highly desirable items, the appreciation of which can affirm one's accumulation of cultural and social capital.

There is, as Peter Brook notes in his essay on melodrama, 'a drama of morality' attached to objects. ${ }^{20}$ We trade them for emotions, for freedom from guilt, for selfesteem, for a sense of identity. A growing number of scholars of consumer culture are now taking note of the drama of morality that dominates the consumption of 
mass produced artefacts today. Consumer habits such as second-hand shopping, foraging and local, fair-trade and free-range consumption movements are being studied as evidence of new modes of 'ethical consumption'.21 One of the most interesting of these moral moves has been the revaluation of artefacts of the past, especially items that originate in the era of burgeoning industrial production of the 1940s, '50s and '60s. In studies of re-consumption of music, fashion, design, furniture, cuisine and even pastimes from earlier cultures, new consumers express the belief that this work constitutes a demonstration of personal values regarding the recuperative possibilities available within consumer culture. 'In a post-industrial world, an object's provenance and aesthetic quality and design history hold more influence than its mere novelty' notes Adrian Franklin: 'Objects with tangible histories of production compare favourably to those created now which have a sort of absence of origin.'22 Old items are desirable not only because they represent an alternative to the present but, more particularly, because they represent an alternative to contemporary modes of consumption and production. As Arjun Appadurai describes, contemporary globalised consumption is serious work for consumers:

the labor of reading ever-shifting fashion messages, the labor of debt servicing, the labor of learning how best to manage newly complex domestic finances, and the labor of acquiring knowledge in the complexities of money management. This labor is not principally targeted at the production of commodities but is directed at producing the conditions of consciousness in which buying can occur ... Every housewife knows that 'housekeeping' is work, as real as any other. We are all housekeepers now, laboring daily to practice the disciplines of purchase in a landscape whose temporal structures have become radically polyrhythmic. ${ }^{23}$

For those who choose to consume vintage, this consciousness is further augmented by the labour of evaluation which involves comparing the relative benefits and deficits of consumer practices, present and past, and the labour of investment, constructing the personal stories attached to the object as is now used and as it once was. Vintage shopping thus requires a form of 'double discipline': the regulation of one's desires in relation to old things as they are now and as they once were. The 
search for 'quality and value' that is the classic hallmark of consumer expertise is extended in vintage shopping to become qualities and values: the discipline of the imagination that can link desire for old commodities because of their apparent novelty in the present with fantasy and nostalgia for a better kind of consumption. For vintage consumers this is serious and often politically, socially and culturally complex work: the past may serve as a 'renewable resource' but this is no guarantee that it is always ethically sound. ${ }^{24}$ It is instructive to observe that just as critics of Mad Men have accused the show of using costumes, objects and design to produce consumer driven nostalgia with scant attention to the politics and history submerged beneath the objects' (reinvested) aura, acts of vintage consumption are likewise subject to similar claims:

That we ... have acquired a passion for things that in another context or time marked the curtailing of women's lives, the treatment of economic hardship as moral deficiency and the cheerful endorsement of non-white people's inferiority bears thinking carefully about as we wander craft markets and vintage frock shops. 25

Unsurprisingly for a show that foregrounds the role of style and design as storytelling devices, Mad Men reflects upon how and why old objects take on particular value in individual lives. An episode in season three uses the redecoration of the Draper living room as an opportunity to explore how individuals express their desires regarding the past and the future through material objects. While Don is discussing a contract that will see him committed to the company for the next three years, Betty hires a professional decorator to give their home a new, modern look. In different ways both are confronting stasis and change as equally troubling options in their personal lives. Betty's dissatisfaction with her home life is mirrored by Don at the office. After a final consultation with the interior decorator, Betty leaves her newly refreshed living room to meet privately with the charming local politician Henry Francis. Betty's attraction to Henry is signalled by the transformative experience of being witness to a solar eclipse, an event that leaves Betty feeling 'a little dizzy'. Henry, helping her to her car, notices a large, pink couch in the nearby antiques store and observes, 'that's what you need'. A fainting couch, Henry goes on to explain, is what Victorian ladies once used whenever they were feeling 'overwhelmed'. Appropriately, Betty falls for the fainting couch and Henry's 
euphemistic recounting of the couch's service to the overcorseted ladies of the Victorian era. She decides to buy it to complement her new redesign at home. of course, it is a disastrous match. As the decorator admonishes:

Decorator: What were you thinking? It's awful.

Betty: It's an antique.

Decorator: We discussed this for months, and we decided antiques were expected. Look around! You have ruined the whole room. ${ }^{26}$

If Betty has ruined the room, she seems unperturbed. By the end of the episode the audience sees the couch, amid modernist designer objects, directly in front of their fireplace (a space the decorator has previously explained is 'the soul of our home'), with Betty comfortably ensconced upon its soft, pink folds. If the modern object embodies the technologically sophisticated and progressive aspirations of the midcentury, Betty's attraction to the antique Victorian sofa reveals a desire to reintroduce some aspect of the past into her modern life. She longs for an object that will connect her to an old (imagined) life; the life of Victorian ladies, with which she senses some connection.

When the decorator curses her romantic infatuation with antiques as wholly too 'expected', modern audiences might sympathise with Betty's desire for something vintage to connect her to an estranged but fascinating past. Betty's desire to bring the antique sofa into the modern living space demonstrates precisely the kind of idiosyncratic labour required for vintage consumption. Vintage goods are valuable to the consumer to the degree that they represent a 'better option', even when the political and social realities represented by these goods are highly problematic. At first glance, Betty's choice seems to demonstrate nothing more than her naive bad taste, but through the context in which her fainting couch is discovered (out on what is effectively a 'platonic' date with another man at a time in her life when it seems that everything is on the brink of change) it is clear that her attachment to the fainting couch has little to do with aesthetics and everything to do with how the imagined history of the object connects with her own experiences in the present. Betty's decision to place a sofa that represents female constriction and frustration in the centre of an otherwise thoroughly modern living room creates an aesthetic dissonance that cannot be ignored. The past, despite its many 
shortcomings, promises the secure territory that the future doesn't offer a housewife.

In the episode's foregrounding of the role of material objects, audiences are instructed to pay attention to the alternative discourse that takes place between items and spectators. The fainting couch is no mere expected antique but an object expression of sublimated and conflicting desires for a more traditional past and a liberated, rebellious future. As Kate Bollick observes, Weiner and his set designers are signposting to audiences the metaphoric language of period objects and the significance they possess beyond their immediate function:

What Weiner is saying with his impeccable sets is that all of these seemingly superficial material things-the god-awful antiques we inexplicably fall for, the 'tasteful' end tables and sofas selected for us by paid experts-are legitimate expressions of who we are. Used correctlythat is to say, digging beneath the notions of what we collectively remember or imagine or wish the 1960s looked like to uncover what was actually available and common at the time, then entering into the minds of the characters to really figure out which choices they, personally, would make-set design is just as revealing as any line of dialogue, visually describing not only individual personalities and their relationships to one another but societal truths, too. 27

Critical responses to Mad Men which fault the show because 'it proceeds, for the most part, like a soap opera' ignore the potential meaning and substance to be found in the show's use of objects. For these critics the use of historically accurate props and costumes can only be used to create authentic 'signs of the times' but can never offer a commentary on the social and cultural phenomena equal to "believable conflicts between personality and situation'.28 Despite these complaints, there exists a substantial body of film scholarship that draws attention to the way in which props and costumes are foregrounded in costume films, period pieces and melodramas (film genres often maligned for their conservative politics and nostalgic social discourses). In analysing such genres, scholars point to the alternative narratives that are established via the metaphoric language of period objects and actions. Often, as Sue Harper notes, 'the spectator is aware that objects possess a 
significance beyond themselves and their immediate function, but ultimately [is] excluded from their exact codified meaning'.29

In her essay on the phenomenon of retro shopping, Kaja Silverman observes how consumers use second-hand shopping as way to engage with the past. Silverman suggests that retro is not evidence of contemporary amnesia or a straightforward nostalgia, but is, rather, a practice that demonstrates how the past exists through textual traces in a cultural and ideological conversation with the present. She describes retro shopping as a dialogue between consumers and clothes; a private conversation exclusive of the official narratives of history. Such habits present a challenge to the usual understanding of time and textuality: shoppers do not approach artefacts from the past as part of any objective history to be found in textbooks but as personal items connected to highly subjective histories of use. As Silverman says, 'by recontextualising objects from earlier periods within the frame of the present, consumers 'reread' them in ways that maximise their transformative potential'. ${ }^{30}$ While there remains a tendency to dismiss consumption, even various forms of 'ethical consumption', as essentially trivial, these consumer reengagements with the material culture of the past demonstrate a how previous eras might be reappropriated for the present in a manner which challenges typical preconceptions. It is usual, for example, to consider that the only place the past occupies for the present popular culture is as empty stereotypical referent, in the style of television shows or films such as Happy Days or Austin Powers, or indeed 'high-brow' period equivalents such as the Merchant Ivory films, yet the current popularity for a program such as Mad Men and its association with vintage consumption suggests that modern consumers are interested in personal engagements with the past of a sort distinct to the kind of 'blank nostalgia' considered the hallmark of 1980s and '90s popular culture.

In Frederic Jameson's influential theory of postmodern nostalgia the historical past was replaced by fashionable and glossy pastness; actual memories of the past substituted with cultural stereotypes which come in turn to constitute the memories of pop culture consumers. In this view, nostalgia ceases to be an emotion tied to real experience and becomes a media mode-a stylistic simulation because the past has become fundamentally estranged. ${ }^{31}$ However, recent historians of nostalgia have shown persuasively that it is possible to consume a past that is not one's own 
without falling into the 'trap' of postmodern simulacra. Conventional conceptions of nostalgia stress the personal aspect of the phenomenon, assuming the fantasy of nostalgia stems inevitably from some fragment of actual experience. Fred Davis' sociological study of nostalgia articulates this common understanding:

the weight of testimony seems to suggest ... that the past which is the object of the nostalgia must in some fashion be a personally experienced past rather than one drawn solely, for example, from chronicles, almanacs, history books, memorial tablets, or, for that matter legend. (Can I be nostalgic for the Ganges, a place I have never seen, or you for the Crusades, a time when you have never lived?) ${ }^{32}$

Davis implies that the answer is no, yet there now exists a wealth of evidence that as an affect and a cultural style nostalgia has become divorced from a necessary concept of personal loss-objects and images of and from the past can be understood in other ways that aren't necessarily to do with first-hand yearning. In Svetlana Boym's The Future of Nostalgia, the author identifies a form of 'reflective' nostalgia that, contrary to traditional configurations which promise to take us 'back home', instead prioritises the individual experience of longing and loss, emphasising the imperfect process of remembrance and the ultimate unknowability of the past. Boym explains:

Re-flection suggests new flexibility, not the reestablishment of stasis. The focus here is not on recovery of what is perceived to be an absolute truth but on the meditation on history and passage of time ... Reflective nostalgia cherishes shattered fragments of memory and temporalizes space ... It reveals that longing and critical thinking are not opposed to one another, as affective memories do not absolve one from compassion, judgment or critical reflection. 33

This kind of nostalgia is not conservative, does not constrict meaning: by using the past as an exploratory vehicle through which to understand the inexplicability of our desires and our origins this activity opens out into questions of knowledge and belief, it seeks to explore configurations and conceptions of time and the cultural and social politics by which it is contextualised.

Instead of starting from the assumption that nostalgia is a typically unreflective form of memory, we might say that it gives sensory depth to 
our awareness of the other places, times and possibilities that are at once integral to who we are and definitively alien to us. In that sense, nostalgia always has the potential to function as a kind of critical selfconsciousness. 34

Rather like Silverman's theory of the dialogue between consumer and object and between past and present in the act of retro shopping, this nostalgic mode is best approached not as naturalised 'home-coming' but as point of departure: an exploration of the creative 'constructed-ness' of personal history.

Weiner's construction of Mad Men makes it clear that he understands his audience share this attitude. Using the complex personal history of his protagonist Don Draper, Weiner demonstrates how it is possible to be nostalgic for a past that is not one's own. Dick Whittaker, formerly the bastard child of a prostitute, becomes Don Draper all because of an opportunistic moment on the battlefields in Korea whereby he is able to claim another man's identity as his own. Effectively Dick Whittaker lives a 'second-hand' life as Don Draper-he inherits a war widow, a new hometown, even a medal of honour. Contrary to those critics who suggest Mad Men's audience popularity is attributable to the second-hand gratification of watching the poor impulse control of its leading characters, the show's driving narrative concentrates on the discipline involved in the 'morality of objects': Don's daily labour to make personal meaning from the artefacts of his life. Like the labour of the vintage consumer, Don's life is lived in 'reflective mode' reliant on reappropriation and remediation. The show hints that this ability to understand the links between objects and desires gives Don a special advantage on Madison Avenue. When the executives from the Kodak company meet with the advertising heads at Sterling Cooper to discuss how best to promote their new invention, a cartridge for loading slides into home-projectors, Don tells them definitively their product needs a namechange. 'It's not called the Wheel, it's called the Carousel,' he says, sensing that it is not the practical but the emotional aspects of the new product that will count with consumers. 'It lets us travel the way a child travels, round and around and back home again, to a place where we know we are loved.' As he speaks slides of the Draper family are shown-happy, candid portraits of the all-American life. Only the television audience knows the unhappy reality that lurks beneath these projected images of the 'real' life of Don Draper: the secret of Dick Whittaker, a marriage in 
breakdown and pressures at work. ${ }^{35}$ In recognising the value in naming the device 'the Carousel', Don demonstrates that he understands the essential human drive to reclaim and refashion the past according to present day desires and requirements. Turning 'round and around and back home again' does not mean a literal homecoming (something neither possible nor desirable for a man like Don), but rather the ongoing process by which our past is constructed according to our present desires. Any nostalgic pangs for a lost time or place are self-consciously creative; historical reality and its textual presentation are collapsed-the inescapability of textuality is made apparent, and embraced.

This sense of personal history operating in ongoing 'carousel mode' also illustrates the degree to which new technology comes to influence our understanding of time and experience. The era of digital technology has transformed our ability to access, circulate, and consume the cultural past and this has made memory 'a matter of perpetually reconfigurable random access'. 36 Boym connects the reflective nostalgic mode to the effects of modern day technologies and the cultural and social changes brought about by globalisation:

The ambivalent sentiment permeates twentieth-century popular culture, where technological advances and special effects are frequently used to recreate visions of the past, from the sinking Titanic to dying gladiators and extinct dinosaurs. Somehow progress didn't cure nostalgia but exacerbated it. Similarly, globalization encouraged stronger local attachments. In counterpoint to our fascination with cyberspace and the virtual global village, there is a no less global epidemic of nostalgia, an affective yearning for a community with a collective memory, a longing for continuity in a fragmented world. ${ }^{37}$

Indeed, it is not only communities but families that are influenced by this technologically enhanced yearning for collective memory and imagined continuity. The longing to make personal meaning of the past recurs as one of Mad Men's principle themes. In an interview with the New York Times Weiner explains, 'part of the show is trying to find out—-this sounds really ineloquent-trying to figure out what is the deal with my parents' ${ }^{38}$ Although initially dismissing Mad Men as a retro fashion trend, one of the 'many fads that take the form of infatuations with certain 
moments in the past', Mendelsohn observes that the show's vintage aesthetic essentially represents a child's eye view of the past.

If so much of Mad Men is curiously opaque, all inexplicable exteriors and posturing, it occurs to you that this is, after all, how the adult world often looks to children; whatever its blankness, that world, as recreated in the show, feels somehow real to those of us who were kids back then. ${ }^{39}$

Mendelsohn considers the popularity of the program, and particularly the popularity of its period aesthetics, might owe something to the fact that it captures the sentiment of those attempting to engage with the world of their parents, using vintage artefacts to uncover the hidden meanings of their origin. The popularity of Mad Men among younger audiences, and the combination of this with other consumption habits such as vintage collecting, points towards the pleasures to be found in discovery and reclamation of the material history of one's unknown past. Critical responses to Mad Men which fault the show for promoting indulgent consumer nostalgia fail to take into account how the show's popularity dovetails with the development of new cultures of nostalgic reconsumption and reclamation. The vintage aesthetic has emerged in a cultural moment in which consumers are able to access, circulate, and reconfigure the textual traces of the past in new and dynamic ways; this involves a reconfiguration of nostalgia, dislocating it from any specific meaning in the past. 40 As Boym notes, the proliferation of nostalgia in popular culture must be set in relation to the significance of new technologies that allow audiences to rescue, recycle and reconfigure the past in the cultural and media terrain. The proliferation of nostalgic modes, genres and styles reflects an engagement with the past based on cultural mediation and textual reconfiguration in the present via particular representational and taste regimes. The popularity of the period details Mad Men carefully foregrounds should not be mistaken as evidence of a straightforward nostalgia for the 'good old days' but rather, as demonstration of a desire on the part of the shows' creators and its audience to reappropriate, reinterpret and reread the past according to alternative narratives informed by present day discourses regarding personal identity and provenance. If the reclamation and reconsumption of the past can be said to have become an established cultural style it is not a result of a crisis of loss, but rather, through a 
surfeit of information technology and global flows, it is what we have gained-new markets for old things.

Caroline Hamilton is a McKenzie Fellow with the Publishing and Communications program at the University of Melbourne. She is presently working on a study of the work lives and culture of Australian small publishers and freelancers. She is also coediting an issue of Cultural Studies Review on the subject of 'amateur economies' to be published in 2013 .

\footnotetext{
-NOTES

1 Mary McNamara , 'Back When Men Were “Mad Men"', Los Angeles Times, 19 July 2007, <http://www.heraldnet.com/article/20070719/ENT/707190301> (accessed 30 January 2012).

2 See comments section in Maureen Ryan, 'Wild about Mad Men: A Talk with Creator Matthew Weiner', Chicago Tribune, 15 October 2007,

<http://featuresblogs.chicagotribune.com/entertainment_tv/2007/10/mad-about-mad-m.html> (accessed 20 Dec 2011).

3 The show's return for season 5 attracted its highest ever audience of 3.5 million. To put this in perspective, in the United States when the current most popular TV show, Two and a Half Men, returned to screens late 2011 it attracted an audience of 27.7 million.

${ }^{4}$ Jesse McLean, Kings of Madison Avenue: The Unofficial Guide to Mad Men, ECW Press, Toronto, 2009; Natasha Vargas Cooper, Mad Men Unbuttoned: A Romp through 1960s America, Harper Collins, New York, 2010; Andrew Cracknell, The Real Mad Men: The Remarkable True Story of Madison Avenue's Golden Age, Quercus, London, 2011.

5 Avi Salzman, 'Analyst: Mad Men Deal with Netflix Should Spur Lions Gate', Barrons, 7 April 2011. <http://blogs.barrons.com/stockstowatchtoday/2011/04/07/analyst-mad-men-deal-with-netflixshould-spur-lions-gate/>, accessed 23 January 2012.

6 Mark Greif, 'You'll Love the Way it Makes You Feel', London Review of Books, 23 October 2008, pp. 1516, <http://www.lrb.co.uk/v30/n20/mark-greif/youll-love-the-way-it-makes-you-feel> (accessed 30 November 2011).

7 Daniel Mendelsohn, 'The Mad Men Account', New York Review of Books, 24 February 2011, <http://www.nybooks.com/articles/archives/2011/feb/24/mad-men-account/?pagination=false> (accessed 30 November 2011).

8 Patrick Radden Keefe, 'Week 3: Is Mad Men Just a Guilty Pleasure?', Slate, 1 September 2009,
} 
<http://www.slate.com/id/2225274/entry/2226904/> (accessed 24 Nov 2011).

${ }^{9}$ Andrew Higson, 'The Heritage Film and British Cinema' in Dissolving Views: Key Writings on British Cinema, ed. Andrew Higson, Oxford University Press, Oxford, 1996, pp. 232-49.

10 Martin A. Hipsky, 'Anglofil(m)ia: Why Does America Watch Merchant Ivory Movies?', Journal of

Popular Film and Television, vol. 22, no. 3, 1994, p. 98.

11 Peabody Award website, Winners 2007,

<http://www.peabody.uga.edu/winners/details.php?id=2473> (accessed 31 March 2012).

12 Lorin Clarke, 'What the Don Has Done', Big Issue, 26 October 2010, p. 14.

${ }^{13}$ Ann Deslandes, 'Flea Market Ethics', New Matilda, 16 March 2010,

<http://newmatilda.com/2010/03/16/flea-market-ethics> (accessed 19 December 2011).

14 Deirdre van Dyk, '10 Questions: Mad Men creator Matthew Weiner', Time, 3 April 2008,

<http://www.time.com/time/specials/2007/style_design/article/0,28804,1727737_1727746_172698

2,00.html> (accessed 15 February 2012).

15 Neil Midgley, 'Matthew Weiner on Creating Mad Men', Telegraph, 15 January 2010,

<http://www.telegraph.co.uk/culture/tvandradio/6997918/Matthew-Weiner-on-creating-Mad-

Men.html>.

16, 'Mad Men Yourself', AMC Mad Men website, <http://www.amctv.com/madmenyourself/> (accessed 13 March 2012).

17 Elizabeth E. Guffey, Retro: The Culture of Revival, Reaktion Books, London, 2006, p. 25.

18 Grant McCracken, Culture and Consumption: New Approaches to the Symbolic Character of Consumer Goods and Activities, Indiana University Press, Bloomington, 1988, p. 54.

19 Guffey, p. 3.

20 Peter Brook, 'The Melodramatic Imagination' in Imitations of Life: A Reader on Film and Television Melodrama, ed. Marcia Landy, Wayne State University Press, Michigan, 1991, p. 64.

${ }^{21}$ See for example Tania Lewis and Emily Potter (eds), Ethical Consumption: A Critical Introduction, Routledge, New York, 2010.

${ }^{22}$ Adrian Franklin, 'The Ethics of Second-Hand Consumption' in Lewis and Potter (eds), p. 165.

23 Arjun Appadurai, Consumption Duration and History in Modernity at Large: Cultural Dimensions of Globalization, University of Minnesota Press, Minneapolis, 2000, pp. 82-3.

${ }^{24}$ R.A. Peterson, Creating Country Music: Fabricating Authenticity, Chicago University Press, Chicago, 1997, p. 220, qtd in Sharon Zukin, 'Consuming Authenticity', Cultural Studies, vol. 22, no. 5, 2008, pp. $724-48,726$.

25 Deslandes.

26 'Seven Twenty Three', Mad Men, season 3, episode 7.

27 Kate Bollick, 'The Fainting Couch for Best Supporting Actor', Slate, 28 September 2009,

$<$ http://www.doublex.com/section/arts/fainting-couch-best-supporting-actor?page $=0,0>$ (accessed 23 February 2012). 
${ }^{28}$ Mendelsohn.

${ }^{29}$ Sue Harper, 'Sexuality in Costume Melodrama' in Gainsborough Melodrama, ed. Sue Harper and Robert Murphy, BFI, London, 1983, p. 50.

30 Kaja Silverman, 'Fragments of a Fashionable Discourse' in Studies in Entertainment: Critical Approaches to Mass Culture, ed. Tania Modleski, Indiana University Press, Bloomington, 1986, p. 150. 31 Frederic Jameson, Postmodernism, or the Cultural Logic of Late Capitalism, Verso, New York, 1991.

32 Fred Davis, Yearning for Yesterday: A Sociology of Nostalgia, Free Press, New York, 1979, p. 8.

33 Svetlana Boym, The Future of Nostalgia, Basic Books, New York, 2002, pp. 49-50.

34 Nadia Atia and Jeremy Davies, 'Nostalgia and the Shapes of History', Memory Studies, vol.

3, no. 3, 2010, p. 184

35 'The Wheel', Mad Men season 1, episode 13.

${ }^{36}$ Jim Collins, Architectures of Excess: Cultural Life in the Information Age, Routledge, New York, 1995, p. 45.

37 Boym, p. xiv.

38 Alex Witchell, “'Mad Men” has its Moment', New York Times, 22 June 2008,

<http://www.nytimes.com/2008/06/22/magazine/22madmen-t.html?pagewanted=all> (accessed 12 March, 2012).

39 Mendelsohn.

40 One of the best examples of this newly technologised vintage aesthetic include the smart phone apps such as Instagram which allow users to add filters to digital photographs to make images appear older, faded and dated in ways that suggest earlier eras of media development (sepia tone, kodachrome, polaroid and so on). 